\title{
Transverse load carrying capacity of steel triangularly corrugated web beam with opening
}

\author{
Sergey Kudryavtsev ${ }^{1, *}$ \\ ${ }^{1}$ Ural Federal University, Department of Building Structures and Soil Mechanics, Mira Street 17a, \\ Yekaterinburg 620002, Russia
}

\begin{abstract}
The paper presents a study of the transverse bending behaviour of corrugated web beam with and without web openings. Examined steel beams consist of two flanges and a thin triangularly corrugated web, connected by automatic welding. In the literature, the influence of web opening over transverse load carrying capacity was dealt with mostly for steel beams with plane, sinusoidal and trapezoidal corrugated webs, so researches of beams with triangularly corrugated webs were found out to be very limited. A parametric study is carried out for various web slenderness and corrugation densities. A general-purpose finite element analysis software ABAQUS was used. The corrugation densities adopted in this study represent practical geometries, which are commonly used for such structures in building practice. Models with and without web openings were analysed and examined in terms of load-deformation characteristics and ultimate web shear resistance. Recommendations are given for the practical design of corrugated web beams weakened by circular openings.
\end{abstract}

\section{Introduction}

Corrugated web beams are fabricated structures with a thin-walled corrugated web and flanges made of plate steel. Currently, such beams used as ceiling girders in multi-story apartment houses, large span roof girders in industrial and administrative buildings etc. In the world practice of construction, sections with trapezoidal, sinusoidal and triangular corrugation profiles are used. Various types of web corrugation are shown in fig. 1.

Triangularly corrugated webs have several advantages over others. For example, they do not require expensive equipment for the production and the webs could be thicker than sinusoidal ones and therefore could resist heavier loads. Due to its profiled form, corrugated web exhibits enhanced shear stability and therefore eliminate the need for additional transverse stiffeners or thicker web plates. In structures of various buildings for operational reasons, it is necessary to lay ventilation, heating, water supply and other pipelines, which requires making holes in the beam webs. Near the opening in the corrugated web there is a concentration of stresses, with the greatest stresses being several times greater than the socalled "medium stresses", which can cause to the destruction of entire structure.

\footnotetext{
*Corresponding author: s.v.kudryavtsev@urfu.ru
} 

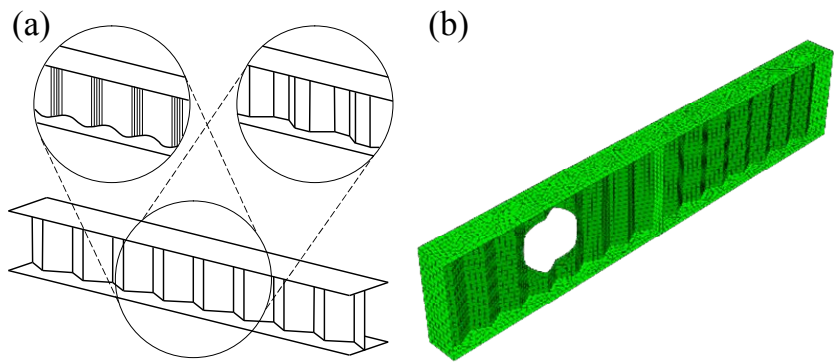

(c)

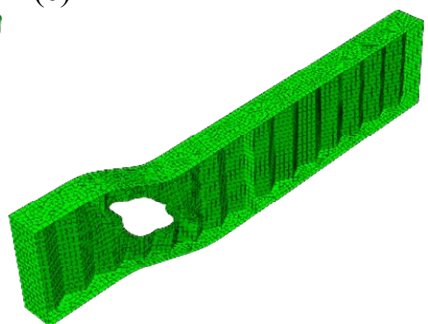

Fig. 1. (a) Beam with sinusoidal, trapezoidal and triangularly corrugated web; (b) Typical FE model adopted for the analysis with web opening; (c) Deformed shape of structure at ultimate load

In the literature, the web opening problem in steel beams was dealt with mostly for steel beams with plane web plates [1]. Research studies on the effect of an opening on a corrugated web were very limited. Furthermore, in current practical design guides [2, 3] there aren't any recommendations for corrugated steel webs with web openings.

In 1994 Lindner and Huang [4] were carried out an investigation of girders with trapezoidal corrugated web plates with cut outs. The study is focused on the local buckling behaviour of these girders with web openings. Romeijn, Sarkhosh and Hoop in 2009 [5] present a parametric study on steel girders with trapezoidal corrugated webs having cut outs. Finite element analysis (FEA) is used to investigate the effect of cut outs in corrugated webs. Openings were considered on the flat plate parts of the trapezoidal web and the effect of various geometric parameters was investigated. Kiymaz, Coskun E, Coskun C and Seckin in 2010 [6] performed a FEA on series of models of beams with sinusoidal corrugation with different corrugation density and different relative opening diameters. In recent years there have been several publications on a similar topic by De'nan and Mustar in 2012 [7], by Krishnarani and Mohanan in 2016 [8] and by Krishnarani and Krishna in 2016 [9], by De'nan, Hasan and Keong in 2017 [10]. In these papers, beams with a triangular corrugated and simultaneously perforated web are considered. In these works, the openings in the web are considered primarily to reduce the weight of the whole structure. Cyclic performance and energy absorption capacity assessment of trapezoidal corrugated webs with perforation were conducted by Bahrebar, Kabir, Zirakian, Hajsadeghi and Lim in 2016 [11]. Bending behaviour of triangularly corrugated web beams weakened by a circular opening was investigated by Kudryavtsev in 2018 [1]. In this work, the stress concentration factors near the circular opening were obtained and it was concluded that the opening in the zone of pure bending had practically no effect on the load-bearing capacity of the beam, whereas opening in the transverse bending zone caused a significant reduction in the bearing capacity of the entire beam.

In present work, a numerical parametric study was carried out for simply supported corrugated web beams with web opening in zone of transverse bending - see fig. 2 . Beam models were examined in terms of the ultimate shear resistance and load-deformation characteristics of the structure.

\section{Design of triangularly corrugated web steel beam}

Limit states considered for the design of a corrugated web beam is, in general, like those for a steel plate girder with a flat web. Rules for design of steel members with trapezoidal and sinusoidal corrugated webs are given in European EN 1993-1-5 [2] and in Russian design code SP 294.1325800.2017 [3]. Unfortunately, in these rules web openings in corrugated webs are not considered. Design features of triangularly corrugated web beams are given in manual [12]. 
(a)
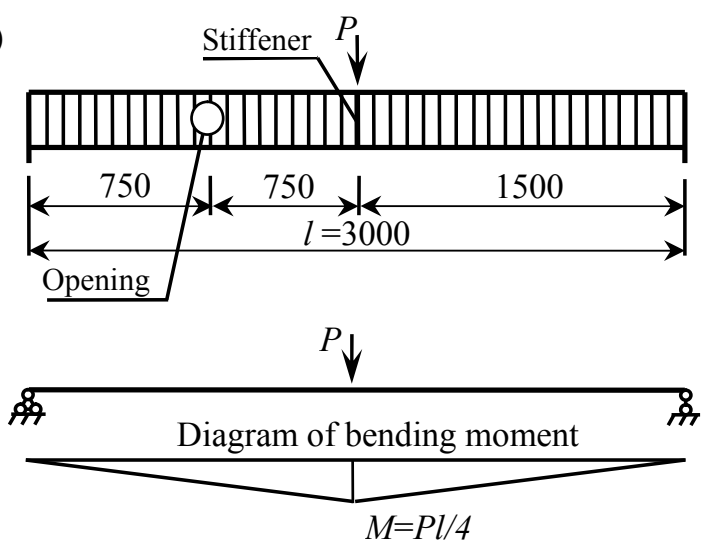

Diagram of shear force

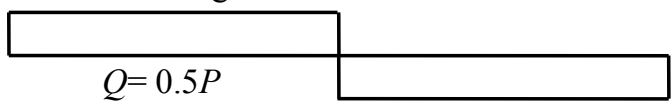

(b)

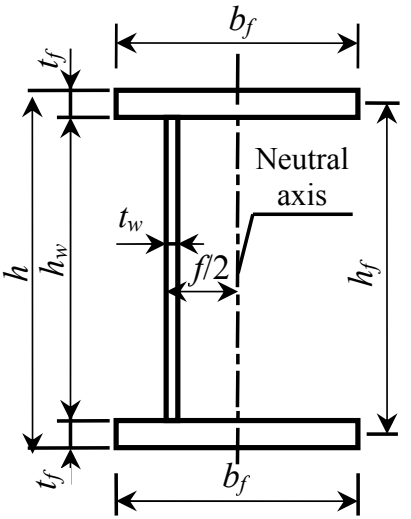

(c)

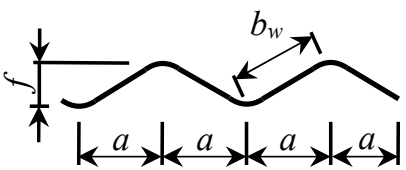

Fig. 2. (a) Considered beam design scheme; (b) Cross section of beam with corrugated web; (c) Geometrical parameters of the corrugated web with triangular shaped corrugations.

Since the corrugated web is not supposed to resist axial forces due to the so-called "accordion effect" [4, 12], corrugated web beams subjected to bending are designed considering that only the flanges resist the bending. On the other hand, shear action is assumed to be carried by the web alone. At the limit state, maximum shear stresses in the corrugated web should not exceed the shear strength of steel which according to the different design recommendations $[2,3,12]$ can be expressed as

$$
\tau_{w}=\frac{Q}{t_{w} h_{w}} \leq \frac{R_{y}}{\sqrt{3}} \gamma_{c},
$$

in which $R_{y}$ is the web material yield strength, $\gamma_{c}$ is partial factor which value varies from 0.9 to 1.0 in different design codes and manuals $[2,3,12]$.

Moreover, for triangularly corrugated web critical shear stresses for local and global buckling should not be less than maximum shear stresses in the web. For corrugated web global buckling represents a diagonal tension field type of buckling of the web whereas local buckling is more localized over a single wave of corrugation or the flat plate of triangular corrugation. It can be expressed according to manual [12]

$$
\begin{gathered}
\tau_{w} \leq \tau_{c r, l}=\frac{0.65 C_{c r, l} R_{y}}{\bar{\lambda}_{c}{ }^{2}} \gamma_{c}, \\
\tau_{w} \leq \tau_{c r, g}=\frac{0.65 C_{c r, g} R_{y}}{\bar{\lambda}_{w}{ }^{2}} \gamma_{c},
\end{gathered}
$$

in which $\tau_{c r, l}, C_{c r, l}$ and $\tau_{c r, g}, C_{c r, g}$ are respectively critical shear stresses of local and global web buckling and numerical factors depending on ration between web height $h_{w}$ and corrugation width $b_{w}$ respectively, $\bar{\lambda}_{c}=b_{w} / t_{w} \sqrt{R_{y} / E}$ and $\bar{\lambda}_{w}=h_{w} / t_{w} \sqrt{R_{y} / E}$ are nondimensional slenderness of corrugation panel and corrugated web respectively.

It should be remarked that local and global critical shear stresses depend mainly on corrugation density and web height. For practical corrugation densities along with common web heights up to $1000 \mathrm{~mm}$ are obtained that critical shear stresses are greater by several folds than the shear strength of web steel so the web carrying capacity depends only on shear yielding by expression (1). 


\section{Numerical parametric study}

Typical finite element (FE) model adopted for the study is shown in fig. 1. A type of fournode doubly curved shell element (S4R) which is available in ABAQUS 2017 was employed in the models. Models are composed of upper and lower flanges of $20 \mathrm{~mm} \mathrm{x}$ $200 \mathrm{~mm}$ in size, representing a plate $200 \mathrm{~mm}$ wide and $20 \mathrm{~mm}$ thick and corrugated web with height of $600 \mathrm{~mm}$ and thickness $3 \mathrm{~mm}, 4 \mathrm{~mm}$ or $5 \mathrm{~mm}$ for different cases. Such relativity thick flanges were used to avoid local buckling of compressed flange in the current study. Also, to avoid local stresses under applied load in the models were added transverse stiffeners at the middle of the span and at the supports of the beam.

For the webs were assumed three different thicknesses $t_{w}=3 \mathrm{~mm}, t_{w}=4 \mathrm{~mm}, t_{w}=5 \mathrm{~mm}$ and three different corrugation densities $f / a=50 \mathrm{~mm} / 100 \mathrm{~mm}, f / a=60 \mathrm{~mm} / 150 \mathrm{~mm}$ and $f / a=70 \mathrm{~mm} / 200 \mathrm{~mm}$. Such corrugation parameters represent practical geometries, which are commonly used for such structures in building practice [12]. For the all models were chosen relatively small span $l=3 \mathrm{~m}$ to avoid flange yielding and so that structural failure occurs due to shear stresses under transverse force. All models were loaded by one-point load $P=1 \mathrm{kN}$ located in the middle of the span on the upper flange at the level of the beam centre line.

In the models, web circular opening is created on one side of the beam. The centre of the opening is located at quarter span point at $750 \mathrm{~mm}$ from the left cover plate at the neutral axis of the beam. Within the parametric study, four different opening sizes which are expressed as the ratio of the opening diameter to web height $d / h_{w}$ is equal to $0.2,0.4,0.6$ and 0.8 were adopted.

Boundary conditions were applied to either ends of the beam models by restraining appropriate degrees of freedom to simulate the simply supported condition and lateral restrains on beam supports and at the middle of the beam to avoid lateral torsional buckling of the structure. An elastic-perfectly plastic material model was assumed with a yield strength value of $240 \mathrm{MPa}$, modulus of elasticity $\mathrm{E}=206000 \mathrm{MPa}$ and Poisson's ratio 0.3 .

Nonlinear geometrical effects are automatically included in the calculation. The nonlinear response and ultimate strength of the models were examined through finite element analysis by the Riks method realized in ABAQUS 2017. This method uses the load magnitude as an additional unknown and solves simultaneously for loads and displacements. The solution is obtained as a series of increments, with iterations to obtain equilibrium within each increment.

\section{Results of the parametric study}

In this work, all models were assumed to transverse bending under perfect conditions, where there are no initial imperfections and eccentricity of load. Deformed shape after the attainment of ultimate load is shown in fig. 1.

In the case under consideration critical applied transverse force for web shear yielding using expression (1) can be obtained as

$$
P_{u l t}=2 \frac{R_{y}}{\sqrt{3}} t_{w} h_{w} \gamma_{c}
$$

To normalize results obtained from FEA in this study was calculated reduction factor $\chi_{0}$ that is shows the effect of the web opening on the transverse load carrying capacity of the beam. It can be expressed as

$$
\chi_{\mathrm{o}}=P_{u l t, 0} / P_{u l t, F E}
$$


in which $P_{u l t, 0}$ is ultimate transverse force for beam without opening and $P_{u l t, F E}$ is ultimate transverse force for beam with opening obtained from the FEA. Ultimate transverse loads and the values of the reduction factors obtained from the non-linear FE analysis for the models are given in Table 1.

Table 1. Results obtained from the non-linear finite element analysis and calculated reduction factors

\begin{tabular}{|c|c|c|c|c|c|c|}
\hline \multirow{2}{*}{ Model } & \multicolumn{3}{|c|}{$P_{\mathrm{ult}, \mathrm{FE}, \mathrm{kN}}$} & \multicolumn{3}{|c|}{$\chi_{0}$} \\
\hline & $t_{\mathrm{w}}=3 \mathrm{~mm}$ & $t_{\mathrm{w}}=4 \mathrm{~mm}$ & $t_{\mathrm{w}}=5 \mathrm{~mm}$ & $t_{\mathrm{w}}=3 \mathrm{~mm}$ & $t_{\mathrm{w}}=4 \mathrm{~mm}$ & $t_{\mathrm{w}}=5 \mathrm{~mm}$ \\
\hline fla: $50 / 100$ no opening & 498.72 & 663.85 & 808.36 & 1.00 & 1.00 & 1.00 \\
\hline fla: $50 / 100 \mathrm{~d} / h_{\mathrm{w}}: 0.2$ & 313.45 & 416.66 & 528.83 & 0.63 & 0.63 & 0.65 \\
\hline fla: $50 / 100 \mathrm{~d} / h_{\mathrm{w}}: 0.4$ & 203.62 & 268.18 & 367.19 & 0.41 & 0.40 & 0.45 \\
\hline fla: $50 / 100 \mathrm{~d} / h_{\mathrm{w}}: 0.6$ & 179.62 & 221.12 & 264.04 & 0.36 & 0.33 & 0.33 \\
\hline$f / a: 50 / 100 d / h_{\mathrm{w}}: 0.8$ & 140.68 & 161.62 & 182.50 & 0.28 & 0.24 & 0.23 \\
\hline fla: $60 / 150$ no opening & 497.95 & 663.57 & 806.67 & 1.00 & 1.00 & 1.00 \\
\hline fla: $60 / 150 \mathrm{~d} / h_{\mathrm{w}}: 0.2$ & 311.33 & 441.34 & 579.22 & 0.63 & 0.67 & 0.72 \\
\hline fla: $60 / 150 \mathrm{~d} / h_{\mathrm{w}}: 0.4$ & 179.27 & 242.44 & 313.74 & 0.36 & 0.37 & 0.39 \\
\hline fla: $60 / 150 \mathrm{~d} / h_{\mathrm{w}}: 0.6$ & 149.42 & 196.18 & 248.28 & 0.30 & 0.30 & 0.31 \\
\hline fla: $60 / 150 \mathrm{~d} / h_{\mathrm{w}}: 0.8$ & 111.33 & 137.69 & 167.30 & 0.22 & 0.21 & 0.21 \\
\hline fla: $70 / 200$ no opening & 497.77 & 663.57 & 808.95 & 1.00 & 1.00 & 1.00 \\
\hline fla: $70 / 200 \mathrm{~d} / h_{\mathrm{w}}: 0.2$ & 228.84 & 355.93 & 492.20 & 0.46 & 0.54 & 0.61 \\
\hline$f / a: 70 / 200 \mathrm{~d} / h_{\mathrm{w}}: 0.4$ & 176.88 & 247.57 & 325.16 & 0.36 & 0.37 & 0.40 \\
\hline fla: $70 / 200 \mathrm{~d} / h_{\mathrm{w}}: 0.6$ & 138.56 & 178.10 & 226.36 & 0.28 & 0.27 & 0.28 \\
\hline$f / a: 70 / 200 \mathrm{~d} / h_{\mathrm{w}}: 0.8$ & 114.65 & 147.17 & 178.42 & 0.23 & 0.22 & 0.22 \\
\hline
\end{tabular}

Analyzing the results, as predicted by expression (4) critical transverse force does not depend on corrugation density and depends only on web thickness. The values of reduction factors are practically independent of the slenderness of the corrugated web i.e. web thickness $t_{w}$ and slightly depend on the corrugation density. It means that the diameter of web opening becomes the dominant factor that controls resistance of the structure. For the models considered in this study, introducing a web opening causes strength reduction between around $37 \%$ up to $78 \%$. As the opening size increases, the percentage reduction values also increase.

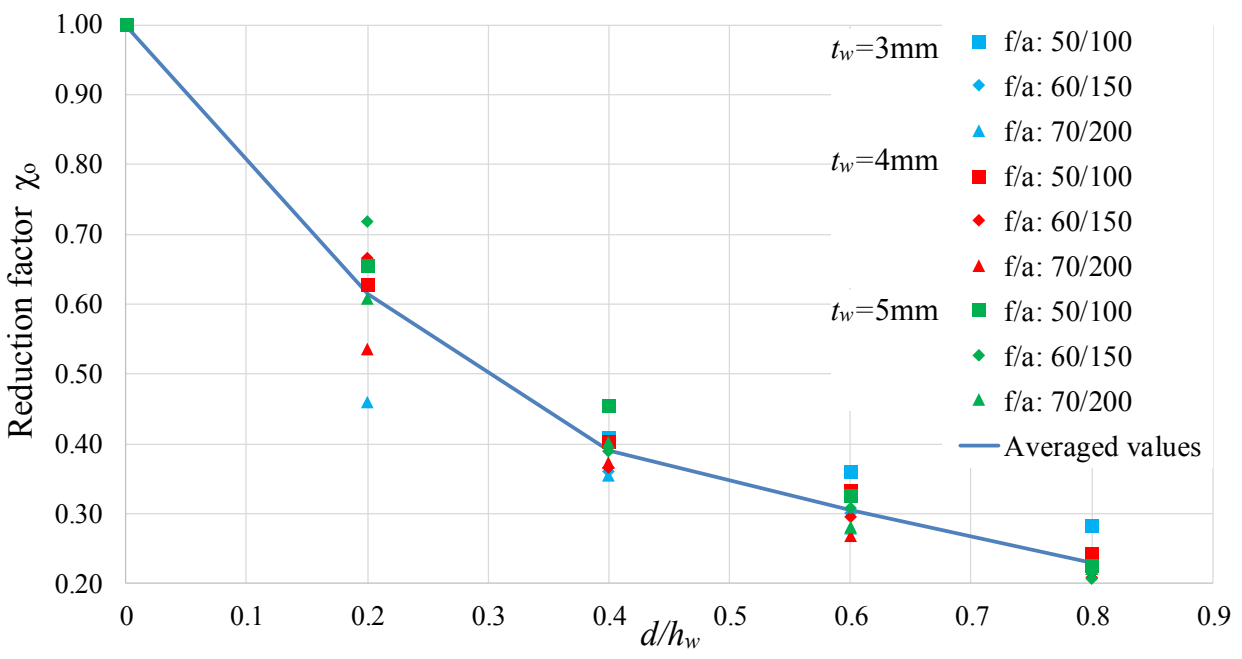

Fig 3. Reduction factors $\chi_{0}$ obtained from FEA and the proposed graph of its averaged values. 
Generalizing the results, in fig. 3 is given a graph shows the dependence of the averaged values of reduction factor $\chi_{0}$ on the relative diameter of the web opening, that can be recommended for practical evaluation of web opening influence on the transverse load carrying capacity for steel triangularly corrugated web beam.

\section{Conclusions}

In present work an investigation into the behavior and design of triangular corrugated steel web beams with web openings was carried out. A general-purpose finite element analysis program was used, and numerical parametric study was carried out for simply supported corrugated steel web beams of $3 \mathrm{~m}$ span and with web openings at quarter of the span. Within the parametric study were considered different opening size, slenderness and the corrugation density of the web. The chosen models represented practical geometries in terms of production and structural application.

According to the results of the performed work, it is shown that existing European [2] and Russian [3] design codes are not perfect in the matter or evaluation of web opening effect on the corrugated web beam loading capacity. So, for practical design procedure, it is recommended to pay respect to decrease of the transverse carrying capacity of the corrugated web beam with an opening by multiplication of its ultimate shear force calculated by relevant design code on reduction factor $\chi_{0}$ obtained in the present work. Surely the issue of the influence of openings in the web for such structures requires further investigation considering initial imperfections, relative size and location of the opening across web height or beam length, the influence of different types of opening reinforcement like rings, stiffeners and so on.

\section{References}

1. S. Kudryavtsev, IOP Conf. Ser.: Mater. Sci. and Eng., 365, 042034 (2018)

2. EN 1993-1-5, Eurocode 3: Design of steel structures - Part 1-5: Plated structural elements, European Committee for Standardization (2006)

3. SP 294.1325800.2017, Steel Structures. Design Rules, Ministry of Construction of Russia (2017)

4. J. Lindner, B. Huang, Progress in the Analysis of Beams with Trapezoidally Corrugated Webs The 17th Czech and Slovak Intern. Conference on Steel Structures and Bridges, Bratislava, II, 151-156 (1994)

5. A. Romeijn, R. Sarkhosh, H. de Hoop, J. Constr. Steel Res., 65, 2, 395-407 (2009)

6. G. Kiymaz, E. Coskun, C. Cosgun, E. Seckin, Steel Compos. Struct., 10, 1, 69-85 (2010)

7. F. De'nan, M. Mustar, Proc. of Int. Conf. on Science and Social Sciences, 20-22 November 2012, 617-621 (2012)

8. K.K. Krishnarani, N. Mohanan, Int. Res. J. of Eng. and Tech. (IRJET), 3, 8, 717-720 (2016)

9. K.K. Krishnarani, S. Krishna, Int. J. for Res. in App. Sci. and Eng. (IJRASET), 4, IX, 161-165 (2016)

10. F. De'nan, H. Hasan, C.K. Keong, Engineering Heritage Journal, 1, 29-35 (2017)

11. M. Bahrebar, M.Z. Kabir, T. Zirakian, M. Hajsadeghi, J.B.P. Lim, J. Constr. Steel Res., 122, 584-594 (2016)

12. S.V. Kudryavtsev, Calculation and design of welded I-section with corrugated webs, (2017) 